\title{
Education of Socialist Core Values Based On Hierarchical Identification
}

\author{
Li Xiaojuan \\ School of Maxim, Zhejiang University \\ Hangzhou, China \\ lxj@zufe.edu.cn
}

\author{
Ma Jianqing \\ School of Maxim, Zhejiang University \\ Hangzhou, China \\ majq2007@163.com
}

\begin{abstract}
Value is the most profound element in determining the nature and orientation of a culture. Socialist core values represent the nucleus of Chinese characteristic culture in the new era. The education on socialist core value purports to enhance individuals' acknowledgement. Based on such theoretical frameworks as modern expectancy value theory, self-efficacy theory, and reinforcement theory, the paper contrives to classify identification into five dimensions in a progressive manner, namely theoretical identification, benefit identification, emotional identification, faith identification, and behavior identification. The relation between the aforementioned five types can be graded systematically, or be independent from each other. The results of teaching of socialist core values will be embodied in the transition of from a superficial level of identification to more profound one. Understanding individuals' hierarchy of identification, and boosting their educational confidence in accordance with the law of mental development, as well as gradually promoting people's identification with mainstream ideology, is supposed to be what the education on socialist core values should be oriented towards.
\end{abstract}

Keywords-Socialist core values; Identification; Hierarchy of identification

\section{INTRODUCTION}

Culture constitutes an important force that sustains the survival and development of a nation. Without the dissemination and prosperity of Chinese culture, by no means can the rejuvenation of the Chinese nation and Chinese dream be crystallized. Socialist core values play a pivotal role in social culture and represent the most profound element in defining the nature and orientation of culture as well as serve as an important stabilizer of the nation. In February 24, 2014, on the thirteenth group study among the members of the Political Bureau of the Central Committee, president $\mathrm{Xi}$ Jinping mentioned that "core values stand for the soul of cultural soft power, and the focal point of the construction of cultural soft power. It is the deepest element in deciding the nature and direction of the culture. The cultural soft power of a nation, in the final analysis, hinges on the vitality, cohesion, and inspiration of its core values." Socialist core values signify the kernel of Chinese characteristic culture in the new era. To cultivate and carry forward the socialist core values, it entails the facilitation of individuals' recognition of socialist core values in the first place. The comprehension of the connotation and psychological levels will push forward the education on core values towards a more lucid and targeted direction.

\section{THE HIERARCHY OF IDENTIFICATION}

As an academic term, the phrase was first put forth and utilized by Freud. From his perspective, identification is used to embody the convergent process, which individuals seek to be in line with other persons, certain groups, or characters that he wants to imitate, and it is the earliest manifestation of individuals' emotional connection with others [1]. Identification is the process of emotional and psychological convergence that one contrives to be consistent with other people, groups or the person he desires to mimic [2]. Obviously, identification is a psychological process that an individual attempts to simulate and internalize another person or a group's value, regulations, and outlook, and then form his own behavioral mode. From what has mentioned above, identification is a kind of recognition based on affections, and the behavioral intention that is formed and accepted from the bottom of heart.

Behavior, the core values were categorized into three dimensions, namely identification of recognition, identification of emotions, and behavioral identification, which was in full compliance with the mentality and behavioral process. Psychologically, core values represent a more stable attitude that individuals have towards things and the identification of values are finally reflected in the behavior. Hence, the identification of socialist core values mainly involves two processes: the shaping of individuals' attitudes and the transformation from attitudes to behaviors. According to relevant theories in the field of communication studies and psychology, the identification of socialist core values can be divided into more specific levels.

\section{A. Theoretical identification}

The so-called theoretical identification means that individuals have sensual contacts with information through publicity channels, and signifies the process from ignorance to knowing and the identification in the cognitive level. Theoretical identification attempts to answer "what it is", and hence have a comprehensive and accurate understanding of the core conception and contents. Individuals may practice socialist core values only after the proper perception of the correct denotation and connotation of each concept of it. For 
concepts like patriotism, integrity, impartiality, and freedom, it will engender different comprehensions among the general public without a clear-cut demarcation of their connotation, thus leading to misbehaviors and even being misled by some similar concepts of western ideologies. Theoretical identification also tries to solve "why it is", and have a precise grasp of the cultural origins and practical significance of socialist core values. When individuals are able to know both "what it is" and "why it is", they will easily have a deep imprint on and a lucid understanding of what the socialist core values are about, consequently being motivated to practice socialist core values. Theoretical identification has to handle the issue of "who is supposed to identify", which is to have an inkling of the responsibilities that people should assume. If a person does comprehend the connotation of each concept of socialist core values in a correct way, but he fails to understand his due share of accountability and even consider it irrelevant to himself, thus it will be difficult for him to practice these values. In this connection, only by the identification of the subject can theoretical identification be endowed with practical meaning.

\section{B. Benefit identification}

The appraisal of the outcome of behaviors is a significant factor that exerts impact on individuals' behavioral motives. According to modern expectancy-value theory, a person's incentives to fulfill various tasks are dictated by his expectation of the possibility of successful completion as well as the value of task. Self-value orientation theory also indicates that whether one's attitude occupies a central position in his personal value system and is of immense significance to him or not functions as an important factor in transforming attitudes to actions. Values reflect the relations between the subject and the object. For individuals, the evaluation of values has a bearing on whether they can suffice their own needs. Once people are disposed to think that practicing socialist core values can meet their needs, they will generate the benefit identification, which serves as an impetus for practice. Only when an individual is aware that practicing socialist core values is closely related to his fulfillment of personal needs, the strong motivation of putting it into practice can be engendered and hence a higher level of identification will be attained.

\section{Emotional identification}

Emotional identification is an emotional acceptance on the basis of theoretical cognizance and value judgment, which shows individuals' assimilation of or compliance with the socialist core values built on their former cognitive schema, representing the process of the shaping of individual attitudes. At the stage of emotional identification, the object of identification has begun to trickle in the deep mental structure of people, and will gradually be "credited" in this process. Emotional identification is connected with the extent to which one's mental or realistic needs have been sufficed. Besides, the judgment of interests constitutes a crucial element that influence individuals' emotions towards the mainstream values. The authority of the institutions that assume the responsibility of educating on core values, the form of information transmission, public trust and others all exert certain impact upon the emotional identification in addition to the judgment of interests.

\section{Faith identification}

Faith identification is what a person seeks to estimate that whether he is capable of practicing certain values and if social climate is suitable for practicing such values or not. Favorable judgments will be conducive to the formation of faith and volition for action. If benefit identification and emotional identification mean a person's willingness to practice core values, then the faith identification can be deemed as the ability to perform it. American psychologist, Bandura, believed that self-efficacy, which signified the belief in individuals' competence in performing certain actions, would have an impact on their behavioral motives, modes of addressing troubles, efforts as well as his emotional experience [3]. The higher one's expected efficacy is, the more proactive he will be, and the harder and more persistently he will work. As a consequence, if people begin to think that practicing socialist core values is beneficial to both themselves and society, and they are eligible for the task, they will have a strong motivation and the will to practice them and even hurdle the difficulties they may encounter during the process. On the contrary, even individuals embrace the socialist core values mentally without a slight sense of skepticism, but they tend to deem that they are incompetent or lack of opportunity to take actions, in this case they can only identify with those core values psychologically, and may fail to turn them into actual actions.

\section{E. Behavioral identification}

Behavioral identification represents the final and genuine materialization of ideology in the realm of conduct, marking the completion of identification. In line with Bandura's triadic reciprocal determinism, the conduct of a person is affected by external environment with the exception of being influenced by one's internal factors such as sentiments, willpower and others. Whether circumstances are favorable to the practice of values, whether such behaviors are really acceptable to society, and whether the expectation of the outcome of the conduct is positive or not will all have an effect on behavioral identification. Besides, a fine example also plays an important role in behavioral identification. [4] Society's positive reinforcement of role models will radically facilitate individuals' propensity to behave similarly. Therefore, individuals' behavioral identification entails corresponding social security mechanism due to the fact that if people constantly suffer setbacks and adversities while practicing socialist core values, which will engender a pernicious social effect, and totally ruin the result of education and dissemination of core values, rendering it difficult for them to have a sense of security in actual practice and really identify with those values.

Meanwhile, the aforementioned six hierarchies of identification also reflect the general process of ideological identification, which can be either gradually progressive or leapfrogged directly with the realization of the previous level of identification serving as a premise for its following one. However, some individuals can reach a higher level of identification, showing that the identification of socialist core 
values can be leapfrogging. This is closely intertwined with one's psychological schema and his own self cultivation, as well as external environment. Generally speaking, a given hierarchy of identification will be conducive to the identification of its ensuing one.

\section{THE STRATEGY OF HIERARCHIAL EDUCATION ON SOCIALIST CORE VALUES}

In view of the fact that identification is hierarchical, the education on socialist core values should also be stratified by a further insight into the psychological evolvement of identification, deepening the teaching of core values in a progressive fashion, so that individuals can eventually act in accordance with the socialist core values.

\section{A. Boosting the confidence and initiative in the education of socialist core values by means of making an appropriate appraisal of its outcome}

Based on the analysis of the hierarchy of identification, for one thing, the result of the education on socialist core values is manifested in citizens' behaviors. For another, it is also embodied in the fact that identification is deepened in a progressive and graded manner. Built on this reality, educators will be apt to observe and evaluate the effect of inculcation of core values from multi-faceted perspectives, thus boosting education confidence. Definitely, the gradual deepening process of hierarchical identification may be implicit, but a thorough understanding can be acquired via conducting questionnaires, surveys or interviews with people, which may require educators to devote more time and energy to further elaborating the teaching of socialist core values.

\section{B. Gradually deepening the teaching of socialist core values by comprehending individuals' hierarchy of identification and law of mental development}

\section{1) Enhance educators' theoretical attainment:}

As what has been discussed before, making efforts to provide scientific explanations for questions like "what it is" and "why it is" related to socialist core values will facilitate individuals' comprehension and identification, which necessitates the profound theoretical accomplishment of educators. Schools of higher learning and research institutions, owing to their easy access to abundant researching resources and capabilities of conducting the in-depth and theoretical study on the education of socialist core values, are supposed to assume the responsibility of channeling theoretical guidance for the teaching. In the same vein, government establishments and organs should pool various useful resources to assist the preaching of core values via different means, seek to collaborate with organizations like schools, research institutes, and government organs to train educators, and carry out the education on socialist core values together, which can render the publicity job more professional and ensure the quality as well. Additionally, educators ought to enhance their theoretical knowledge by constant self-study and have a genuine perception and understanding of as well as faith in core values, so that they can better conduct the ideological education among residents.

\section{2) Enrich the channels of theoretical teaching:}

The perception and learning is a process that involves attention, memory and apprehension. Theoretical propaganda of socialist core values should observe the principle of being meaningful, engaging and easy to remember, avoid being vapid and tedious in terms of form and content. While conducting the education on socialist core values, the professionalism of theory and the vivacity of teaching and publicity are complementary. It will be easier for educators to convert theoretical knowledge into plain language and vivid forms if they have a solid theoretical foundation. For instance, by utilizing billboard, showcase, banner and electronic display and the like, educators can adapt the contents of core values into songs, poems or short verses that can be readily chanted by people. In addition to spreading the contents of socialist core values, publicity work should also further expound on such issues as "how to carry out it", "why doing it" and "who is supposed to do", and inculcate them with precepts like "patriotism is not about sabotaging your compatriots' imported cars", "pursuing self-improvement and working hard", "honesty is the gold, which can be used to win other's trust", "those who is committed to his work are respectable" and so forth. On account of its vast space, showcase can be drawn on to make more detailed explanations on socialist core values and the location and layout of it all have a bearing on the effect of the publicity, which renders meticulous design and conception indispensable. Schools can incorporate the theories and contents pertinent to socialist core values by virtue of ideological and political course, campus cultural activities and so on, thus indoctrinating those values in students in an unwitting way.

3) Satisfy the basic needs of members of society will facilitate their emotional acceptance of government institutions and educators who are responsible for the teaching and publicity of socialist core values:

According to communication theory, it is easier for audiences to accept information if they have affinity with communicators. In the same vein, once theoretical educators or relevant departments win citizens' trust and recognition, the philosophy they preach will be more readily accepted by the vast majority of people. Individuals tend to have positive emotions and feelings if their own needs are sufficed. In line with Maslow's hierarchy of needs, people have fundamental physiological needs such as material needs so as to maintain their own subsistence. If government organs can try their best to solve the difficulties that people encounter, for example, providing care for lonely senior citizens and left-behind children, satisfying their basic needs, in this way the public can easily have emotional identification with the government. Meanwhile, government institutions should set good examples, which will improve their authority and credibility among citizens and be of help to the implementation of education on socialist core values. 
4) Instruct individuals to have higher level of need, and promoting the emotional identification of socialist core values among social members:

Socialist core values per se are a high level of mental state. However, individuals also have high levels of psychological needs, such as the needs of respect, social interactions, selfrealization and others [5]. Socialist core values, in essence, contrive to fulfill those needs, provided that high levels of psychological needs must be activated and instructed. For educators who attempt to carry out the education on socialist core values can, at least, try the following two ways. In the first place, they ought to combine the construction of social climate with the interests of citizens. What every citizen aspires for are a country featuring prosperity, strength, democracy, advanced culture, and harmony, and a society of freedom, equality, justice and lawful governance, which can guarantee their legitimate rights and interests. Nevertheless, to build such a country and society call $\mathrm{s}$ for the participation and perspiration of each citizen. According to the aforementioned two points, the state and society's pursuits should be combined with the pursuit of values of the mass. In the second place, individuals' needs of development should be combined with the practice of socialist core values. Values like patriotism, dedication, integrity and friendship are norms and requirements that members of society are supposed to follow and meet in order to attain favorable development. Prior to the proposal of socialist core values comprising 24 Chinese characters, they have already functioned as the norms and regulations that restrict people's codes of conduct. Once individuals are conscious of the fact that the establishment of socialist core values is closely connected with their happy lives, they will act voluntarily to incorporate it into the hope for the destiny of the country and the requirement of themselves.

5) Create favorable social climate and cultural atmosphere, paying attention to providing incentives for practicing socialist core values and advancing individuals' behavioral identification:

Circumstances are latent factors that have influence on individuals' behaviors, while social climate and cultural atmosphere are important aspects of external environment. Whether citizens can persist in practicing socialist core values, to a large extent, hinges on the fact that if society can provide them with a sensation of security, honor, dignity, and gain. Thus, individuals' practice of socialist core values is inextricably linked with the cultural atmosphere of external environment. For instance, if a department considers mutual assistance as its core culture, friendly people can gain more respect and pleasure in such an environment and other people will be more likely to practice the value of friendliness. On the contrary, in a department where helping others is deemed as suffering loss and being stupid, the value of friendliness may be neglected or even ridiculed, hence seriously undermining practitioners' enthusiasm and making it difficult for the socialist core values to be identified. Consequently, favorable social climate and cultural atmosphere may serve as a strong spiritual motivation for people and provide instructions for them at the same time, while unpleasant ambience can be counterproductive. To create a favorable social climate, society has to reward good behaviors with prompt and effective incentives either materially or spiritually, and inflict punishments upon perpetrators, which calls for further improvements of social establishments.

\section{CONCLUSION}

In conclusion, when educators or relevant departments can consciously apply the law of individuals' psychological identification, it is easier for them to make breakthroughs and gradually provide guidance for people in the course of teaching and dissemination of socialist core values, thus yielding tangible results.

\section{REFERENCES}

[1] Wang Yapeng, "The status quo of ethnic identity research," Advances in Psychological Sciences.Beijing, vol.10, pp.102. January 2003.

[2] Che Wenbo, The Freud doctrine principle. Liaoning People's Press. Shenyang, pp.375. September 1988.

[3] A.Bandura, "The explanatory and predicitive scope of self-efficacy theory," Journal of Clinical and Social Psychology. America, vol.4, pp.359-373. March 1986.

[4] A.Bandura, Self-efficacy: The implementation of control. East China Normal University Press. Shanghai,PP543.December 2003.

[5] Abraham H.Maslow, Motivation and Personality. China Renmin University, pp290. July 2012. 